\title{
Pioglitazone - A Bullet for Many Targets!
}

\author{
Deepalakshmi M, Haritha Atluri, Arun KP*
}

Department of Pharmacy Practice, JSS College of Pharmacy, JSS University, Ooty, Tamil Nadu, INDIA.

\begin{abstract}
Obesity and aging has resulted ever increasing incidence of type 2 diabetes in many developing countries including India. Among the various classes of anti-diabetic agents including being used in the clinics, thiazolidinediones (TZDs) comprise important class which is Peroxisome Proliferator-Activated Receptor Gamma (PPARG) agonists. This article reviews the Pharmacology of Pioglitazone beyond its anti-diabetic effect. Thorough literature search was done including e-resources to understand the clinical evidences for the anti-diabetic and extra anti diabetic activities of Pioglitazone. Pioglitazone is known to successfully control the HbA1c levels not only in many patients with Type 2 diabetes but, also in pre-diabetic subjects. We generally use lower doses of Pioglitazone (about $30 \mathrm{mg}$ ) in India and so it will take longer time to reach the cumulative dose, and if use the dose of $7.5 \mathrm{mg}$, it would take even longer time close to 10 years. Thus, low dose Pioglitazone has been very widely used due to its efficacy and lower frequency of side effects including weight gain and fluid retention. It can be concluded that the literature evidences suggest that Pioglitazone has acceptable safety profile, many extra anti diabetic effects including cardiovascular and pleotropic effects apart from its use in Type 2 diabetes patients and pre-diabetic individuals.
\end{abstract}

Key words: Pioglitazone, PPARgamma agonists, Type 2 diabetes, Extra anti diabetic effect.

\section{INTRODUCTION}

An overall prevalence of diabetes has been reported to be about $7 \%$ with a range of $4.3 \%$ to $10 \%$ in a recent survey conducted across 15 states in India. ${ }^{1}$ Pre-diabetes also known as intermediate hyperglycemia is the state in which glycemic variables are greater than the normal values but lesser than the threshold values of diabetes and these subjects are at high risk to develop diabetes. Literature shows that annually about 5 to $10 \%$ of the pre-diabetic subjects either develop diabetes or revert to normoglycemia. ${ }^{2}$ Pre-diabetes is characterized by both insulin resistance and $\beta$-cell failure which further relate to the future type 2 diabetes. Pre-diabetes is determined by Impaired Glucose Tolerance (IGT) or Impaired Fasting Glucose (IFG). IFG is diagnosed if the fasting blood glucose level is measured between 100 to $125 \mathrm{mg} / \mathrm{dL}$ after overnight fasting and does not fit into the criteria for diabetes $(\geq 126 \mathrm{mg} / \mathrm{dL}){ }^{3}$ IGT is diagnosed if the glycemic level is measured between 140 to $199 \mathrm{mg} / \mathrm{dL}$ at 2 hours of Oral Glucose Tolerance Test (OGT'T) and does not fit into the criteria for diabetes which is $\geq 200 \mathrm{mg} / \mathrm{dL}$. However, both the parameters indicate a contrasting insulin response with one another during OGTT. ${ }^{4}$ Early insulin response during an OGTT and muscle insulin sensitivity is seen in patients with IFG. Late insulin response and high muscle insulin resistance is shown by patients with IGT.

In insulin resistance syndrome, various risk factors like glucose intolerance, hyper insulinaemia, obesity, dyslipidemia and low-grade inflammation known to pose cardiovascular threat. Although treatment of these individual risk factors reduces cardiovascular complications, focusing the underlying pathophysiological mechanisms responsible for insulin resistance syndrome is more judicious therapy for improving the overall therapeutic outcome.

Peroxisome Proliferator-Activated Receptors (PPARs) are ligand-activated transcription factors which regulate the expression of various genes responsible for both glycemic and non-glycemic effects. PPAR gamma
DOI: 10.5530/ijopp.11.1.2

Address for correspondence: Dr Arun K P, M.Pharm., Ph.D.,

Assistant Professor Department of Pharmacy Practice JSS College of Pharmacy Ooty-643001, The Nilgiris Tamil Nadu, INDIA

kparun@jssuni.edu.in

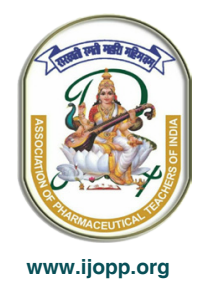


sub type activation leads to improving insulin sensitivity. This sub type of transcription factors is also involved in the process of atherosclerosis, which is responsible for various cardiovascular events. Thiazolidinediones (TZDs) are PPAR-gamma agonists and constitute an important class of pharmacological agents for the treatment of type 2 (non-insulin-dependent) diabetes mellitus. Apart from glycemic control, the non-glycemic effects of TZDs include beneficial influence on lipid metabolism, blood pressure, endothelial function, atherosclerotic plaque, coagulation, and albuminuria. Thus, TZDs are valuable for both diabetes and patients with pre-diabetes. ${ }^{5}$

\section{PIOGLITAZONE}

Pioglitazone is one of the three drugs in the class of thiozolidinediones and the only drug available in this class at present in many of the countries across the globe. The drug which was approved in the year 1999 had reached Indian market in the late 2000. Though this drug was suspended in the mid of 2013 by the drug regulators in India, the suspension was revoked swiftly within a short span and made available again with an updated warning for the patients about the risk of bladder cancer. Pioglitazone is used as a mono therapy or in combination with insulin, Metformin or Sulfonylureas when diet, exercise, and a single agent do not result in adequate glycemic control. Although current labeled uses of this drug do not involve pre-diabetes or the metabolic syndrome, the practitioners are using these drugs in both the conditions due to their extra-glycemic effects mentioned earlier.

\section{GLYCEMIC EFFECTS OF PIOGLITAZONE}

Studies have shown that in diabetic patients, TZDs reduces glycated hemoglobin A1c (HbA1c) by 5-18 $\mathrm{mmol} / \mathrm{ml}$ when compared with placebo. ${ }^{6}$ Pioglitazone is known to lower plasma glucose in type 2 diabetes mellitus patients through multiple pathways viz. increasing insulin sensitivity, decreasing endogenous glucose production and postprandial gluconeogenesis, increasing fasting and postprandial glucose clearance and finally have beneficial effects on beta cell function. The dose of Pioglitazone ranges from 15-30 $\mathrm{mg}$ per day with a maximum dose of $45 \mathrm{mg}$ every day. ${ }^{7}$

\section{PIOGLITAZONE IN PREVENTION OR DELAYING OF DIABETES MELLITUS}

Thiazolidinediones are effective in preventing IGT progression to type 2 diabetes mellitus as these agents play dual role by improving insulin sensitivity and preserving $\beta$-cell function. These mechanisms were proven in various clinical studies which include but not limited to Troglitazone in the Prevention of Diabetes (TRIPOD) study, Pioglitazone in the Prevention of Diabetes (PIPOD) study, Diabetes Reduction Assessment with Ramipril and Rosiglitazone Medication (DREAM) study, and Actos Now for the Prevention of Diabetes (ACT NOW) study. These corrections of pathophysiological abnormalities have shown to prevent progression of IGT to type 2 diabetes. ${ }^{8}$ ACT NOW is a double blind, placebo controlled randomized study. The study population was 602 patients with type 2 diabetes mellitus having IGT. The median follows up was 2.4 years. Results from ACT NOW depicted that Pioglitazone (45 mg/day) decreased IGT conversion to type 2 diabetes by $72 \% .{ }^{9}$ The Pioglitazone group showed an annual incidence of $2.1 \%$ type $2 \mathrm{DM}$ when compared to placebo group (7.6\%). Pioglitazone has reduced the levels of fasting glucose by $11.7 \mathrm{mg} / \mathrm{dL}, 2 \mathrm{~h}$ glucose by $30.5 \mathrm{mg} / \mathrm{dL}$ and $\mathrm{HbA} 1 \mathrm{c}$ by $0.04 \%$. However, weight gain was greater with Pioglitazone, $3.9 \mathrm{~kg}$ vs. $0.77 \mathrm{~kg}$ for placebo, and edema was more frequent $(12.9 \%$ vs. $6.4 \%) .{ }^{10}$

\section{PIOGLITAZONE IN METABOLIC SYNDROME AND DYSLIPIDEMIA}

Metabolic syndrome (MetSyn) is a huddle of metabolic abnormalities that is characterized by abdominal obesity, insulin resistance (IR), dyslipidemia, elevated blood pressure, and a pro inflammatory and prothrombotic milieu. ${ }^{11}$ It was understood that MetSyn increases the probability for the occurrence of both type 2 diabetes mellitus and atherosclerotic cardiovascular disease. It is believed that low levels of high density lipoprotein cholesterol (HDL-C) are commonly seen in patients with MetSyn. ${ }^{12}$ Pioglitazone reduces lipolysis and increases adipocyte differentiation. The high expression of PPAR gamma receptor on adipocyte is believed to be a reason for increased adipocyte differentiation. Hence the increase in glucose uptake by muscle is an indirect effect mediated through Pioglitazone interaction with adipocytes. Although the mechanism of action is unknown, Pioglitazone slightly reduces blood pressure, enhance fibrinolysis, and improve endothelial function. In nondiabetic patients with MetSyn and low HDL-C, Pioglitazone has increased HDL-C by $15 \%$ when compared with placebo within a net period of 6 weeks at $30 \mathrm{mg}{ }^{13}$

\section{PIOGLITAZONE IN CARDIOVASCULAR PROTECTION}

Studies confirmed that in diabetic patients the prognosis of coronary atherosclerosis is high. This aggravates the risk for life threatening cardiovascular events. ${ }^{14}$ Pre-diabetic patients are also considered to be at high risk patients for developing coronary atherosclerosis 
eventually leading to cardiovascular mortality. Various factors like diabetes hyperglycemia including pre diabetes, free fatty acids, and insulin resistance result in mechanisms that alter the function and structure of blood vessels..$^{15}$ the structural changes of blood vessels affect vasoconstriction whereas the functional changes affect the inflammatory process, thereby leading to coronary atherosclerosis which assumedly starts during pre-diabetic state. ${ }^{16}$ Four recent studies, the ACCORD (Action to Control Cardiovascular Risk in Diabetes) study, the ADVANCE(Action in Diabetes and Vascular Disease: Preterax and Diamicron Modified Release Controlled Evaluation) trial, the VADT (Veterans Affairs Diabetes Trial) trial and the United Kingdom Prospective Diabetes Study Post-Trial (UKPDS post-trial) study, suggest that lowering the glucose levels reduces the risk to cardiovascular event. ${ }^{17}$ Pioglitazone is one of the agents known to reduce atherosclerosis In pre diabetic and diabetic patients. Pioglitazone cardiovascular outcomes are studied in PERISCOPE, PROactive and CHICAGO. In PERISCOPE(Pioglitazone Effect on Regression of Intravascular Sonographic Coronary Obstruction Prospective Evaluation), Pioglitazone given at a dose of $15-45 \mathrm{mg} /$ day for over 18 months has significantly delayed the progression of atherosclerosis when compared with Glimepride (1-4mg/day). ${ }^{18}$ In PROactive study Pioglitazone has reduced the macro vascular complications in patients with type $2 \mathrm{DM} .{ }^{19}$ In CHICAGO study (Carotid intima media thickness in Atherosclerosis using Pioglitazone), Pioglitazone at $15-45 \mathrm{mg}$ /day was compared with Glimepiride1-4 mg/day over 18 months in 462 patients of type 2 diabetes. Pioglitazone significantly slowed the progression of carotid intima media thickness (CIMT), a validated measure of arthrosclerosis progression. ${ }^{20}$

\section{POSSIBLE GLYCEMIC AND EXTRA-GLYCEMIC EFFECTS OF PIOGLITAZONE}

\begin{tabular}{cc}
\hline $\begin{array}{c}\text { Possible Effects of } \\
\text { Pioglitazone }\end{array}$ & $\begin{array}{c}\text { Postulated Mechanism for } \\
\text { Pioglitazone Effects }\end{array}$ \\
\hline $\begin{array}{c}\text { Prevention of type } 2 \text { diabetes } \\
\text { mellitus }\end{array}$ & $\begin{array}{c}\text { Improving the insulin } \\
\text { sensitivity and preserving } \\
\text { beta cell functions to prevent } \\
\text { or delay the onset of type } 2 \\
\text { diabetes mellitus. }{ }^{21}\end{array}$ \\
Detabolic Syndrome/Insulin & Decreasing the insulin \\
resistant state & resistance and thereby \\
& decreasing the risk of \\
& embolic syndromes including \\
dyslipidemia, hypertension & and microalbuminuria. ${ }^{22}$ \\
& Increasing the concentration \\
of high density lipoprotein \\
and reducing triglycerides. ${ }^{22}$
\end{tabular}

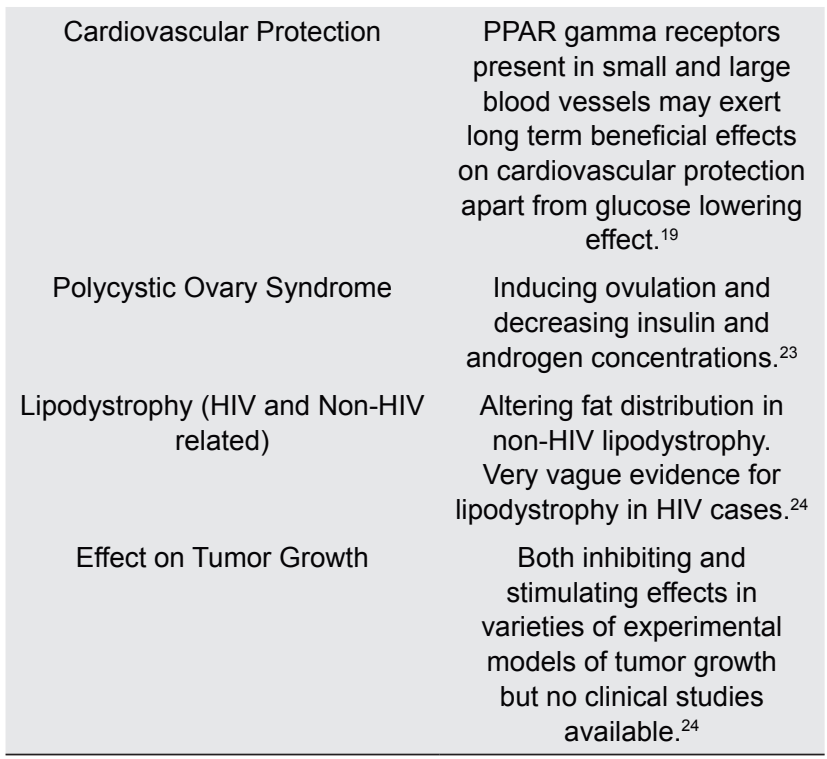

\section{CONCLUSION}

Pioglitazone has been proven for its anti-diabetic efficacy especially valued in the Asian-Indian patients, who have a high level of insulin resistance. Though generally well tolerated, this drug is known to precipitate the most common emergent adverse events such as weight gain and edema. It is also effective in reducing some measures of cardiovascular risks and arteriosclerosis. The recent controversy about this drug about chances of developing bladder cancer has been over ruled because of poor scientific evidence. ${ }^{25}$ Thus Pioglitazone continues to be an effective treatment option for the management of patients with type 2 diabetes.

\section{REFERENCES}

1. Anjana RM, Deepa M, Pradeepa R, Mahanta J, Narain K et al. Prevalence of diabetes and prediabetes in 15 states of India: results from the ICMRINDIAB population-based cross-sectional study. Lancet Diabetes Endocrinol. 2017;5:585-96.

2. Hiranya Kumar Das, Tabak A, Herder C, Rathmann W, Brunner E, Kivim"aki M. Prediabetes: a high-risk state for diabetes development. The Lancet. 2012;379:2279-90.

3. https://www.ncbi.nlm.nih.gov/books/NBK10739/. [Accessed on 5.1.2017]

4. Abdul-Ghani M, Jenkinson C, Richardson D, Tripathy D, DeFronzo R. Insulin secretion and action in subjects with impaired fasting glucose and impaired glucose tolerance results from the veterans administration genetic epidemiology study. Diabetes. 2006;55:1430-5.

5. Spiegelman B. PPAR-gamma: Adipogenic regulator and thiazolidinedione receptor. Diabetes. 1998;47:507-14.

6. Chang F, Jaber L, Berlie H, O'Connell M. Evolution of peroxisome proliferatoractivated receptor agonists. Ann. Pharmacother. 2007;41:973-83.

7. Derosa G, Gaddi A, Piccinni M, Salvadeo S, Ciccarelli L, Fogari E et al. Differential effect of glimepirideand rosiglitazone on metabolic control of type 2 diabetic patients treated with metformin: A randomized, double-blind, clinical trial. Diabetes Obes Metab. 2006;8:197-205.

8. DeFronzo R, Abdul-Ghani M. Type 2 Diabetes Can Be Prevented With Early Pharmacological Intervention. Diabetes Care [Internet]. 2011 [9 June 2014] 34(Supplement_2):S202-S209. Availablefrom: http://dx.doi.org/10.2337/ dc11-s221 
9. Kahn R, Davidson M. The reality of type 2 diabetes prevention. Diabetes care 2014;37:943-9.

10. DeFronzo R, Tripathy D, Schwenke D, Banerji M, Bray G, Buchanan T et al. Pioglitazone for diabetesprevention in impaired glucose tolerance. $\mathrm{N}$ Engl J Med. 2011;364:1104-15.

11. Grundy S. Clinical Management of Metabolic Syndrome: Report of the American HeartAssociation/National Heart, Lung, and Blood Institute/American Diabetes Association Conferenceon Scientific Issues Related to Management. Circulation [Internet]. 2004;109(4):551-6. Available from: http://dx.doi. org/10.1161/01.cir.0000112379.88385.67

12. Ford E, Giles W, Dietz W. Prevalence of the metabolic syndrome among US adults: findings from the third National Health and Nutrition Examination Survey. JAMA. 2002;287:356-9.

13. Szapary P, Bloedon L, Samaha F, Duffy D, Wolfe M, Soffer D, et al. Effects of pioglitazone onlipoproteins, inflammatory markers, and adipokines in nondiabetic patients with metabolicsyndrome. Arterioscler Thromb Vasc Biol. 2006;26:182-8.

14. Stamler J, Vaccaro O, Neaton J, Wentworth D. others. Diabetes, other risk factors, and 12-yrcardiovascular mortality for men screened in the Multiple Risk Factor Intervention Trial. Diabetes care. 1993;16:434-44.

15. Ogawa H, Koyanagi R, Kawada-Watanabe E, Yamaguchi J, Takagi A, Hagiwara N, et al. Eur Heart J. 2012;655-939.

16. Meier M, Hummel M. Cardiovascular disease and intensive glucose control in type 2 diabetesmellitus: moving practice toward evidence-based strategies. Vasc Health Risk Manag. 2009;5:859-71

17. Nissen S, Nicholls S, Wolski K, Nesto R, Kupfer S, Perez A, et al. Comparison of pioglitazone vsglimepiride on progression of coronary atherosclerosis in patients with type 2 diabetes: thePERISCOPE randomized controlled trial. JAMA. 2008;299:1561-73.
18. Dormandy J, Charbonnel B, Eckland D, Erdmann E, Massi-Benedetti M, Moules I. Secondary prevention of macrovascular events in patients with type 2 diabetes: a randomized trial of pioglitazone. The PROactive Study (PROspective pioglitAzone Clinical Trial in macro Vascular Events). Lancet. 2005;366:1279-89.

19. Mazzone T, Meyer P, Feinstein S, Davidson M, Kondos G, D'Agostino R, et al. Effect of Pioglitazone compared with Glimepride on carotid intima-media thickness in type 2 diabetes: a randomized trial. JAMA. 2006;296:2572-81.

20. Walter H, L"ubben G. Potential role of oral thiazolidinedione therapy in preserving beta-cell function in type 2 diabetes mellitus. Drugs. 2005;65:1-13.

21. Derosa G, D'Angelo A, Ragonesi P, Ciccarelli L, Piccinni M, Pricolo F, et al. Metabolic effects of Pioglitazone and Rosiglitazone in patients with diabetes and metabolic syndrome treated with Metformin. Intern Med. 2007;37:79-86.

22. Koo Y, Shin S, Yoon B, Choi D. Pioglitazone for treating polycystic ovary syndrome in non-obesewomen of reproductive age with different clinical presentations. Gynecol Endocrinol. 2007;23:461-7.

23. Slama L, Lanoy E, Valantin M, Bastard J, Chermak A, Boutekatjirt A, et al. Effect of pioglitazone onHIV-1-related lipodystrophy: a randomized doubleblind placebo-controlled trial (ANRS 113). Antivir Ther. 2008;13:67.

24. Mr'owka P, Glodkowska E, Mlynarczuk-Bialy I, Bialy L, Kuckelkorn U, Nowis D, et al. Pioglitazone, aPPAR-gamma ligand, exerts cytostatic/cytotoxic effects against cancer cells, that do not result from inhibition of proteasome. Acta Biochimica Polonica-English Edition. 2008;55:75.

25. Arif Hashmi. Pioglitazone suspension and its aftermath: A wake up call for the Indian drug regulatory authorities. J Pharmacol Pharmacother. 2013;4:227-9. 